\title{
Comorbidities in Patients with Psoriatic Arthritis
}

\author{
Amir Haddad, M.D. ${ }^{1 *}$ and Devy Zisman, M.D. ${ }^{1,2}$ \\ ${ }^{\prime}$ Rheumatology Unit, Carmel Medical Centre, Haifa, Israel; and ${ }^{2}$ The Ruth and Bruce Rappaport Faculty \\ of Medicine, Technion-Israel Institute of Technology, Haifa, Israel
}

\begin{abstract}
Epidemiological studies have shown that patients with psoriatic arthritis (PsA) are often affected by numerous comorbidities that carry significant morbidity and mortality. Reported comorbidities include diabetes mellitus, obesity, metabolic syndrome, cardiovascular diseases, osteoporosis, inflammatory bowel disease, autoimmune eye disease, non-alcoholic fatty liver disease, depression, and fibromyalgia. All health care providers for patients with PsA should recognize and monitor those comorbidities, as well as understand their effect on patient management to ensure an optimal clinical outcome.
\end{abstract}

KEY WORDS: Comorbidity, management, psoriatic arthritis

\section{INTRODUCTION}

Psoriatic arthritis (PsA) is a heterogeneous multifaceted inflammatory arthritis associated with psoriasis; it is considered to be one of the spondyloarthritides and as such has both spinal and peripheral joint involvement as well as enthesitis and dactylitis. In addition to the joint and skin manifestations, PsA is associated with numerous extra-articular immunemediated manifestations such as inflammatory bowel disease and autoimmune ophthalmic disease. Studies have shown that patients with psoriatic disease suffer also from associated comorbidities, including cardiovascular disease, obesity and metabolic syndrome, diabetes, osteoporosis, malignancy, fatty liver disease, depression, and anxiety. ${ }^{1}$ To ensure an optimal outcome, identifying these comorbidities is of utmost importance. The objectives of this review are to present and discuss the available evidence on comorbidities in PsA patients.

\footnotetext{
Abbreviations: CVD, cardiovascular disease; DMARD, disease-modifying antirheumatic drug; IBD, inflammatory bowel disease; LFT, liver function test; NAFLD, non-alcoholic fatty liver disease; NASH, non-alcoholic steatohepatitis; NSAID, non-steroidal anti-inflammatory drug; PsA, psoriatic arthritis; TNFa, tumor necrosis factor alpha.
}

Citation: Haddad A, Zisman D. Comorbidities in Patients with Psoriatic Arthritis. Rambam Maimonides Med J 2017;8 (1):eo004. doi:10.5041/RMMJ.10279 Review

Copyright: (C) 2017 Haddad and Zisman. This is an open-access article. All its content, except where otherwise noted, is distributed under the terms of the Creative Commons Attribution License (http://creativecommons.org/licenses/by/3.0), which permits unrestricted use, distribution, and reproduction in any medium, provided the original work is properly cited.

Conflict of interest: No potential conflict of interest relevant to this article was reported.

* To whom correspondence should be addressed. E-mail: amirha3@clalit.org.il 


\section{CARDIOVASCULAR DISEASE}

Cardiovascular disease (CVD) is one of the most significant comorbidities in rheumatic diseases in general, and in psoriatic disease in particular, where the systemic inflammation leads to increased insulin resistance, endothelial cell dysfunction, and the development of atherosclerosis. ${ }^{2}$ A meta-analysis of 75 observational studies found that psoriasis is associated with a relative risk of 1.4 (95\% CI 1.2-1.7) for CVD. ${ }^{3}$ Although there are fewer studies on cardiovascular risk in PsA compared with that in psoriasis, several studies have shown a similar trend.4,5 A recent population-based cohort study has shown that the risk of major adverse cardiovascular events was higher in PsA patients not prescribed a disease-modifying antirheumatic drug (DMARD) (HR 1.24, 95\% CI 1.03-1.49) compared to the general population after adjusting for traditional cardiovascular risk factors but without increase in mortality. ${ }^{6}$ The association was found to be independent of traditional CVD risk factors such as hypertension, dyslipidemia, and smoking and correlated with markers of disease severity and activity, ${ }^{7}$ suggesting that optimal treatment of the disease would improve CVD outcomes. To date, however, as far as we could find in a far-ranging review of the literature, no study has specifically examined the effect of aggressive PsA treatment regimens on the risk of cardiovascular events. On the other hand, studies on patients with rheumatoid arthritis and psoriasis have shown a reduced rate of cardiovascular events among patients treated with anti-tumor necrosis factor alpha (TNFa) medications. ${ }^{8,9}$ In patients with comorbid CVD, the use of non-steroidal anti-inflammatory drugs should be at the lowest effective dose for the shortest period of time possible. ${ }^{10}$

\section{DIABETES MELLITUS, METABOLIC SYNDROME, AND OBESITY}

Diabetes mellitus, metabolic syndrome, and obesity were reported to be at increased prevalence in many studies on patients with psoriatic arthritis, with a crude OR of 2.18 (95\% CI 1.36-3.50) of type 2 diabetes mellitus in PsA, and patients with severe psoriasis having a higher risk. ${ }^{11-13}$ Among diabetic patients, psoriasis is generally associated with higher rates of microvascular and macrovascular complications. ${ }^{14}$ Patients with PsA have a higher BMI compared to rheumatoid arthritis patients and the general population. ${ }^{15}$ In patients with PsA, metabolic syndrome and insulin resistance are highly prevalent and were found to be independently associated with the severity of underlying PsA.16 Several mechanisms could explain the association between PsA and diabetes, such as patients' unhealthy lifestyle, ${ }^{17}$ the inflammatory cytokine milieu that drives insulin resistance, ${ }^{18-20}$ as well as shared genetic loci for susceptibility to psoriasis and diabetes. ${ }^{21-23} \mathrm{~A}$ large study on patients with PsA conducted in Israel also found an association with diabetes even after controlling for potential confounders, including age, obesity, and steroid treatment. ${ }^{24}$ This finding might also have therapeutic implications, as ongoing studies are investigating the effect of antidiabetic drugs on psoriasis. ${ }^{25,26}$

\section{OSTEOPOROSIS}

Osteoporosis was reported in studies on patients with various inflammatory rheumatic diseases, ${ }^{27-30}$ as well as increased risk for low bone density and fragility fractures. ${ }^{31}$ Skeletal manifestations of PsA are complex and comprise both new bone formation manifesting with bone ankylosis, periostitis, and syndesmophytes, and bone resorption in the form of erosions. The prevalence of osteoporosis in PsA has not been studied to the same degree. The literature review with regard to bone mineral density in PsA shows inconsistent and conflicting results.32-34 Patients with PsA in Israel, however, were also found to be at increased risk of osteoporosis. ${ }^{24}$

\section{INFLAMMATORY BOWEL DISEASE}

Inflammatory bowel disease (IBD) as well as subclinical bowel inflammation have been observed with increased incidence in patients with psoriasis, and a pronounced risk was found in patients with concomitant PsA (RR 6.43, 95\% CI 2.04-20.32) for Crohn's disease but not for ulcerative colitis. 35,36 Occasionally, patients may develop a paradoxical IBD when being treated with an anti-TNFa agent. ${ }^{37}$ One debatable issue is whether non-steroidal antiinflammatory drugs (NSAIDs) may exacerbate IBD symptoms $.3^{8}$ No data have been published assessing the appropriate therapy for concomitant PsA and IBD, although common medications are being used to treat both conditions. Among the anti-TNFa medications, the monoclonal TNFa receptor etanercept was not shown to be effective in treatment of IBD.

\section{AUTOIMMUNE OPHTHALMIC DISEASE}

Autoimmune ophthalmic diseases, including uveitis, keratitis, blepharitis, conjunctivitis, episcleritis, and 
scleritis, have been observed, ${ }^{39-41}$ with uveitis being the most common. ${ }^{42}$ Autoimmune ophthalmic disease often precedes PsA or progresses despite adequate therapy for PsA. As in the management of inflammatory bowel disease, etanercept may not adequately control the uveitis. 43 Moreover, as the case numbers are low, a causative role cannot be discerned with the use of anti-TNFa agents in PsA patients who develop uveitis. 44

\section{MALIGNANCY}

Malignancies increased in patients with systemic autoimmune rheumatic diseases, particularly rheumatoid arthritis, 45 systemic lupus erythematosus, 46 systemic sclerosis, 47 and idiopathic inflammatory myopathies. ${ }^{48}$ Studies on patients with PsA, however, did not show an increased risk of solid malignancies.49 In a meta-analysis of randomized controlled trials (RCTs) across all indications, short-term use of TNFa inhibitors was not associated with a significantly increased risk of cancer..$^{50}$ No statistically significant increase in non-melanoma skin cancers was observed in patients using TNFa blockers. $5^{\circ}$

\section{LIVER DISEASE}

Liver disease, particularly non-alcoholic fatty liver disease (NAFLD), has an increased prevalence in patients with psoriasis. ${ }^{51}$ Few studies have examined this relationship solely in PsA patients.52,53 Among patients with psoriasis, however, an increased prevalence of NAFLD is associated with metabolic syndrome, hypercholesterolemia, hypertriglyceridemia, obesity, psoriasis severity, and concomitant PsA.54 The use of medications such as NSAIDs, DMARDs, and TNFa blockers may be also associated with liver function test (LFT) abnormalities and hepatotoxicity. Higher rates of non-alcoholic steatohepatitis (NASH)/NAFLD may occur in PsA patients using methotrexate compared to rheumatoid arthritis (RA), 55 and LFT abnormalities may be similar or slightly higher in PsA patients.52,53,56 Studies of psoriasis have shown that the development of NASH/NAFLD in long-term users of methotrexate was associated with cumulative doses of methotrexate as well as presence of obesity or diabetes. 57 So patients should be monitored regularly for liver function tests abnormalities; a liver biopsy should be considered, based on the presence or absence of risk factors for hepatotoxicity and cumulative methotrexate dose. 58

\section{DEPRESSION AND ANXIETY}

Depression and anxiety could be related to the impact of psoriasis, arthritis, or inflammation.59 It is estimated to affect more than $30 \%$ of psoriasis patients. ${ }^{60}$ The rate of depression and anxiety was reported to be significantly higher in patients with PsA than in those with psoriasis and was associated with disease-related factors such as actively inflamed joint count as well as disability, pain, and fatigue. ${ }^{61}$ Treatment with TNFa blockers was associated with reduced rates of depression and insomnia, as well as a reduced rate of regular antidepressant use. ${ }^{62}$

\section{FIBROMYALGIA}

Coexisting fibromyalgia should be identified and differentiated from enthesitis. Fibromyalgia was reported in $53 \%$ of patients in one study. ${ }^{63}$ It is related to worse patient-reported outcomes and disease activity measures. The influence of coexisting fibromyalgia should be taken into consideration in the treatment decision, in order to avoid unnecessary treatment escalation. ${ }^{64}$

\section{CONCLUSION}

In this review we have highlighted some important comorbid diseases and extra-articular manifestations that can have an impact on patient care, management, treatment decisions, and quality of life as well as mortality. We recommend that, to provide comprehensive medical care to patients with PsA, physicians should be aware of these comorbid disease associations.

\section{REFERENCES}

1. Husni ME. Comorbidities in psoriatic arthritis. Rheum Dis Clin North Am 2015;41:677-98. Full Text

2. Boehncke WH, Boehncke S, Tobin AM, Kirby B. The 'psoriatic march': a concept of how severe psoriasis may drive cardiovascular comorbidity. Exp Dermatol 2011;20:303-7. Full Text

3. Miller I, Ellervik C, Yazdanyar S, Jemec G. Metaanalysis of psoriasis, cardiovascular disease, and associated risk factors. J Am Acad Dermatol 2013; 69:1014-24. Full Text

4. Han C, Robinson D Jr, Hackett M, Paramore L, Fraeman K, Bala M. Cardiovascular disease and risk factors in patients with rheumatoid arthritis, 
psoriatic arthritis, and ankylosing spondylitis. J Rheumatol 2006;33:2167-72.

5. Gladman D, Ang M, Su L, Tom B, Schentag C, Farewell V. Cardiovascular morbidity in psoriatic arthritis. Ann Rheum Dis 2009;68:1131-5. Full Text

6. Ogdie A, Yu Y, Haynes K, et al. Risk of major cardiovascular events in patients with psoriatic arthritis, psoriasis and rheumatoid arthritis: a populationbased cohort study. Ann Rheum Dis 2014;74:326-32. Full Text

7. Eder L, Thavaneswaran A, Chandran V, Cook R, Gladman DD. Increased burden of inflammation over time is associated with the extent of atherosclerotic plaques in patients with psoriatic arthritis. Ann Rheum Dis 2015;74:1830-5. Full Text

8. Dixon WG, Watson KD, Lunt M, et al. Reduction in the incidence of myocardial infarction in patients with rheumatoid arthritis who respond to anti-tumor necrosis factor alpha therapy: results from the British Society for Rheumatology Biologics Register. Arthritis Rheum 2007;56:2905-12. Full Text

9. Ryan C, Leonardi CL, Krueger JG, et al. Association between biologic therapies for chronic plaque psoriasis and cardiovascular events: a meta-analysis of randomized controlled trials. JAMA 2011;306: 864-71. Full Text

10. US Food and Drug Administration. FDA Briefing Document: Joint Meeting of the Arthritis Advisory Committee and the Drug Safety and Risk Management Advisory Committee on Nonsteroidal Antiinflammatory Drugs and Cardiovascular Thrombotic Risk. February 10-11, 2014. Available at: http:// bit.ly/2gvTCgm.

11. Labitigan M, Bahče-Altuntas A, Kremer JM, et al. Higher rates and clustering of abnormal lipids, obesity, and diabetes mellitus in psoriatic arthritis compared with rheumatoid arthritis. Arthritis Care Res (Hoboken) 2014;66:600-7. Full Text

12. Johnsson H, McInnes IB, Sattar N. Cardiovascular and metabolic risks in psoriasis and psoriatic arthritis: pragmatic clinical management based on available evidence. Ann Rheum Dis 2012;71:480-3. Full Text

13. Coto-Segura P, Eiris-Salvado N, Gonzalez-Lara L, et al. Psoriasis, psoriatic arthritis and type 2 diabetes mellitus: a systematic review and meta-analysis. $\mathrm{Br} \mathrm{J}$ Dermatol 2013;169:783-93. Full Text

14. Armstrong AW, Guérin A, Sundaram M, et al. Psoriasis and risk of diabetes-associated microvascular and macrovascular complications. J Am Acad Dermatol 2015;72:968-77.e2. Full Text
15. Bhole VM, Choi HK, Burns LC, et al. Differences in body mass index among individuals with PsA, psoriasis, RA and the general population. Rheumatology (Oxford) 2012;51:552-6. Full Text

16. Haroon M, Gallagher P, Heffernan E, FitzGerald O. High prevalence of metabolic syndrome and of insulin resistance in psoriatic arthritis is associated with the severity of underlying disease. J Rheumatol 2014;41:1357-65. Full Text

17. Tam LS, Tomlinson B, Chu TT, et al. Cardiovascular risk profile of patients with psoriatic arthritis compared to controls-the role of inflammation. Rheumatology (Oxford) 2008;47:718-23. Full Text

18. Gottlieb AB, Dann F, Menter A. Psoriasis and the metabolic syndrome. J Drugs Dermatol 2008;7:56372.

19. Channual J, Wu JJ, Dann FJ. Effects of tumor necrosis factor-alpha blockade on metabolic syndrome components in psoriasis and psoriatic arthritis and additional lessons learned from rheumatoid arthritis. Dermatol Ther 2009;22:61-73. Full Text

20. Sonnenberg GE, Krakower GR, Kissebah AH. A novel pathway to the manifestations of metabolic syndrome. Obes Res 2004;12:180-6. Full Text

21. Das SK, Elbein SC. The search for type 2 diabetes susceptibility loci: the chromosome 1q story. Curr Diab Rep 2007;7:154-64. Full Text

22. Yoo H, Kim SJ, Kim Y, Lee H, Kim TY. Insulin-like growth factor-II regulates the 12-lipoxygenase gene expression and promotes cell proliferation in human keratinocytes via the extracellular regulatory kinase and phosphatidylinositol 3-kinase pathways. Int $\mathrm{J}$ Biochem Cell Biol 2007;39:1248-59. Full Text

23. Wolf N, Quaranta M, Prescott NJ, et al. Psoriasis is associated with pleiotropic susceptibility loci identified in type II diabetes and Crohn disease. J Med Genet 2008;45:114-16. Full Text

24. Haddad A, Cohen AD, Ashkenazi RI, et al. Endocrine comorbidities in patients with psoriatic arthritis - a population based case controlled study. Oral Presentation, The 2016 GRAPPA Annual Scientific Meeting. Miami, Florida. July 14-16, 2016.

25. Pershadsingh HA. Peroxisome proliferator-activated receptor-gamma: therapeutic target for diseases beyond diabetes: quo vadis? Expert Opin Investig Drugs 2004;13:215-28. Full Text

26. Mastrofrancesco A, Kovacs D, Sarra M, et al. Preclinical studies of a specific PPARY modulator in the control of skin inflammation. J Invest Dermatol 2014;134:1001-11. Full Text 
27. Rossini M, Viapiana O, Adami S, et al. In patients with rheumatoid arthritis, Dickkopf-1 serum levels and correlated with parathyroid hormone, bone erosions and bone mineral density. Clin Exp Rheumatol 2015;33:77-83.

28. Davey-Ranasinghe N, Deodhar A. Osteoporosis and vertebral fractures in ankylosing spondylitis. Curr Opin Rheumatol 2013;25:509-16. Full Text

29. Adachi JD, Lau A. Systemic lupus erythematosus, osteoporosis, and fractures. J Rheumatol 2014;41: 1913-15. Full Text

30. Omair MA, McDonald-Blumer H, Johnson SR. Bone disease in systemic sclerosis: outcomes and associations. Clin Exp Rheumatol 2014;32(6 Suppl 86):S28-32.

31. Maruotti N, Corrado A, Cantatore FP. Osteoporosis and rheumatic diseases. Reumatismo 2014;66:12535. Full Text

32. Grazio S, Cvijetić S, Vlak T, et al. Osteoporosis in psoriatic arthritis: is there any? Wien Klin Wochenschr 2011;123:743-50. Full Text

33. Frediani B, Allegri A, Falsetti P, et al. Bone mineral density in patients with psoriatic arthritis. J Rheumatol 2001;28:138-43.

34. Reid DM, Kennedy NS, Nicoll J, Smith MA, Tothill P, Nuki G. Total and peripheral bone mass in patients with psoriatic arthritis and rheumatoid arthritis. Clin Rheumatol 1986;5:372-8. Full Text

35. Li WQ, Han JL, Chan AT, Qureshi AA. Psoriasis, psoriatic arthritis and increased risk of incident Crohn's disease in US women. Ann Rheum Dis 2013;72:1200-5. Full Text

36. Scarpa R, Manguso F, D'Arienzo A, et al. Microscopic inflammatory changes in colon of patients with both active psoriasis and psoriatic arthritis without bowel symptoms. J Rheumatol 2000;27:1241-6.

37. Toussirot E, Houvenagel E, Goeb V, et al. Development of inflammatory bowel disease during antiTNF- $\alpha$ therapy for inflammatory rheumatic disease: a nationwide series. Joint Bone Spine 2012;79:457-63. Full Text

38. Felder JB, Korelitz BI, Rajapakse R, Schwarz S, Horatagis AP, Gleim G. Effects of nonsteroidal antiinflammatory drugs on inflammatory bowel disease: a case-control study. Am J Gastroenterol 2000;95: 1949-54. Full Text

39. Lambert JR, Wright V. Eye inflammation in psoriatic arthritis. Ann Rheum Dis 1976;35:354-6. Full Text

40. Altan-Yaycioglu R, Akova YA, Kart H, Cetinkaya A, Yilmaz G, Aydin P. Posterior scleritis in psoriatic arthritis. Retina 2003;23:717-19. Full Text
41. Lima FB, Abalem MF, Ruiz DG, et al. Prevalence of eye disease in Brazilian patients with psoriatic arthritis. Clinics (Sao Paulo) 2012;67:249-53. Full Text

42. Zeboulon N, Dougados M, Gossec L. Prevalence and characteristics of uveitis in the spondyloarthropathies: a systematic literature review. Ann Rheum Dis 2008;67:955-9. Full Text

43. Smith JA, Thompson DJ, Whitcup SM, et al. A randomized, placebo-controlled, double-masked clinical trial of etanercept for the treatment of uveitis associated with juvenile idiopathic arthritis. Arthritis Rheum 2005;53:18-23. Full Text

44. Lim LL, Fraunfelder FW, Rosenbaum JT. Do tumor necrosis factor inhibitors cause uveitis? A registrybased study. Arthritis Rheum 2007;56:3248-52. Full $\underline{\text { Text }}$

45. Mellemkjaer L, Linet MS, Gridley G, Frisch M, Møller $\mathrm{H}$, Olsen JH. Rheumatoid arthritis and cancer risk. Eur J Cancer 1996;32A:1753-7.

46. Bernatsky S, Boivin J-F, Clarke A, Rajan R. Cancer risk in systemic lupus erythematosus: a metaanalysis. Arthritis Rheum 2001;44(Suppl 9):S244.

47. Rosenthal AK, McLaughlin JK, Linet MS, Persson I. Scleroderma and malignancy: an epidemiological study. Ann Rheum Dis 1993;52:531-3. Full Text

48. Sigurgeirsson B, Lindelof B, Edhag O, Allander E. Risk of cancer in patients with dermatomyositis or polymyositis. N Engl J Med 1992;326:363-7. Full $\underline{\text { Text }}$

49. Haynes K, Beukelman T, Curtis JR, et al. Tumor necrosis factor alpha inhibitor therapy and cancer risk in chronic immune-mediated diseases. Arthritis Rheum 2013;65:48-58. Full Text

50. Dommasch ED, Abuabara K, Shin DB, Nguyen J, Troxel AB, Gelfand JM. The risk of infection and malignancy with tumor necrosis factor antagonists in adults with psoriatic disease: a systematic review and meta-analysis of randomized controlled trials. J Am Acad Dermatol 2011;64:1035-50. Full Text

51. Madanagobalane S, Anandan S. The increased prevalence of non-alcoholic fatty liver disease in psoriatic patients: a study from South India. Australas J Dermatol 2012;53:190-7. Full Text

52. Curtis JR, Beukelman T, Onofrei A, et al. Elevated liver enzyme tests among patients with rheumatoid arthritis or psoriatic arthritis treated with methotrexate and/or leflunomide. Ann Rheum Dis 2010; 69:43-7. Full Text

53. Tilling L, Townsend S, David J. Methotrexate and hepatic toxicity in rheumatoid arthritis and psoriatic arthritis. Clin Drug Investig 2006;26:55-62. Full $\underline{\text { Text }}$ 
54. Miele L, Vallone S, Cefalo C, et al. Prevalence, characteristics and severity of non-alcoholic fatty liver disease in patients with chronic plaque psoriasis. J Hepatol 2009;51:778-86. Full Text

55. Seitz M, Reichenbach S, Moller B, Zwahlen M, Villiger PM, Dufour JF. Hepatoprotective effect of tumour necrosis factor alpha blockade in psoriatic arthritis: a cross-sectional study. Ann Rheum Dis 2010;69:114850. Full Text

56. Amital H, Arnson Y, Chodick G, Shalev V. Hepatotoxicity rates do not differ in patients with rheumatoid arthritis and psoriasis treated with methotrexate. Rheumatology (Oxford) 2009;48:1107-10. Full Text

57. Rosenberg P, Urwitz H, Johannesson A, et al. Psoriasis patients with diabetes type 2 are at high risk of developing liver fibrosis during methotrexate treatment. J Hepatol 2007;46:1111-18. Full Text

58. Menter A, Korman NJ, Elmets CA, et al. Guidelines of care for the management of psoriasis and psoriatic arthritis: section 4. Guidelines of care for the management and treatment of psoriasis with traditional systemic agents. J Am Acad Dermatol 2009;61:45185. Full Text

59. Rosenblat JD, Cha DS, Mansur RB, McIntyre RS. Inflamed moods: a review of the interactions between inflammation and mood disorders. Prog Neuropsychopharmacol Biol Psychiatry 2014;53:23-34. Full Text

6o. Dowlatshahi EA, Wakkee M, Arends LR, Nijsten T. The prevalence and odds of depressive symptoms and clinical depression in psoriasis patients: a systematic review and meta-analysis. J Invest Dermatol 2014; 134:1542-51. Full Text

61. McDonough E, Ayearst R, Eder L, et al. Depression and anxiety in psoriatic disease: prevalence and associated factors. J Rheumatol 2014;41:887-96. Full $\underline{\text { Text }}$

62. Wu CY, Chang YT, Juan CK, et al. Depression and insomnia in patients with psoriasis and psoriatic arthritis taking tumor necrosis factor antagonists. Medicine (Baltimore) 2016;95:e3816. Full Text

63. Magrey MN, Antonelli M, James N, Khan MA. High frequency of fibromyalgia in patients with psoriatic arthritis: a pilot study. Arthritis 2013;2013:762921. Full Text

64. Brikman S, Furer V, Wollman J, et al. The effect of the presence of fibromyalgia on common clinical disease activity indices in patients with psoriatic arthritis: a cross-sectional study. J Rheumatol 2016;43: 1749-54. Full Text 